\title{
Use of shock index as a prognostic marker in patients with normal heart rate and blood pressure at ICU admission
}

\author{
FG Zampieri ${ }^{1,2^{*}}$, F Colombari $^{1}$ \\ From ESICM LIVES 2015 \\ Berlin, Germany. 3-7 October 2015
}

\begin{abstract}
Introduction
Heart rate (HR) and blood pressure (BP) are two of the most ubiquitous hemodynamic parameters assessed in medicine. Nevertheless, normal values of $\mathrm{HR}$ and BP are not absolute markers of stability. Shock index (SI - ratio between $\mathrm{HR}$ and systolic $\mathrm{BP}$ ) is an important prognosis marker in trauma [1] and has been suggested to be associated with mortality in acutely ill patients even when HR and BP are within the normal range [2]. Intriguingly, there is a lack of data reporting SI as a marker of severity in the intensive care unit. It is especially unclear if SI could be an additional useful parameter in patients with normal values of HR and BP.
\end{abstract}

\section{Objectives}

To assess the association between SI measured at admission and mortality in otherwise stable patients admitted to the ICU. As secondary endpoint, we assessed the association between SI and subsequent need for organ support (vasopressors, mechanical ventilation and renal replacement therapy).

\section{Methods}

Retrospective analysis of all patients admitted from January 2012 until August 2014 in a tertiary ICU in Brazil. Inclusion criteria assessed at ICU admission were:

1) $\mathrm{HR}>50$ and $<100 \mathrm{bpm}$,

2) Systolic blood pressure $>90 \mathrm{mmHg}$,

3) Mean $\mathrm{BP}>65 \mathrm{mmHg}$,

4) Absence of vasopressor use.

Association between SI and hospital mortality and need for organ support was assessed through logistic

${ }^{1}$ Hospital Alemão Oswaldo Cruz, Intensive Care Unit, São Paulo, Brazil Full list of author information is available at the end of the article regression controlling for illness severity (SAPS3 without attributable points for $\mathrm{HR}$ and $\mathrm{BP}$ ).

\section{Results}

3,140 patients were included. Hospital mortality was 5.7\% (179 patients). $7.3 \%$ (231 patients) eventually required vasopressors; $4.3 \%$ (137) required mechanical ventilation and $2.6 \%(83)$ required renal replacement therapy. Higher SI was independently associated with mortality (Figure 1)

An SI greater than 0.7 had an odds ratio for mortality of 1.43 (95\% CI 1.03-2.00; $\mathrm{p}=0.03$ ). A SI value higher than 0.7 was associated with need for starting vasopressors during ICU stay (OR 1.69; 95\% CI 1.28-2.23; p < 0.01). SI was not associated with need for mechanical ventilation or renal replacement therapy. Excluding patients with a known diagnosis of chronic heart failure did not change the results.

\section{Conclusion}

In a population with otherwise stable vital signs at admission, higher SI values were independently associated with

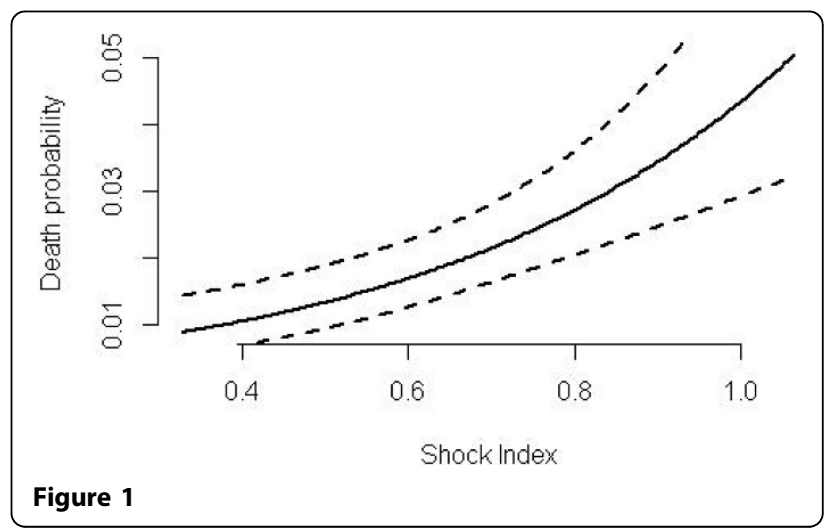

Figure 1

\section{SpringerOpen ${ }^{\circ}$}

(C) 2015 Zampieri and Colombari This is an Open Access article distributed under the terms of the Creative Commons Attribution License (http://creativecommons.org/licenses/by/4.0), which permits unrestricted use, distribution, and reproduction in any medium, provided the original work is properly cited. 
mortality and need for vasopressors. SI should be considered as an additional prognostic marker in this population and may help predicting future hemodynamic instability.

\section{Authors' details}

${ }^{1}$ Hospital Alemão Oswaldo Cruz, Intensive Care Unit, São Paulo, Brazil.

${ }^{2}$ Hospital das Clínicas, University of São Paulo, Intensive Care Unit, São Paulo, Brazil.

Published: 1 October 2015

\section{References}

1. Cannon CM, Braxton CC, Kling-Smith M, Mahnken JD, Carlton E,

Moncure M: Utility of the shock index in predicting mortality in traumatically injured patients. J Trauma 2009, 67(6):1426-1430.

2. Rady MY, Smithline HA, Blake H, Nowak R, Rivers E: A comparison of the shock index and conventional vital signs to identify acute, critical illness in the emergency department. Ann Emerg Med 1994, 24(4):685-690.

doi:10.1186/2197-425X-3-S1-A596

Cite this article as: Zampieri and Colombari: Use of shock index as a prognostic marker in patients with normal heart rate and blood pressure at ICU admission. Intensive Care Medicine Experimental 20153 (Suppl 1):A596.

\section{Submit your manuscript to a SpringerOpen ${ }^{\odot}$ journal and benefit from:}

- Convenient online submission

- Rigorous peer review

- Immediate publication on acceptance

- Open access: articles freely available online

- High visibility within the field

- Retaining the copyright to your article 